\section{Investigando a relação formação médica e atividade física: significa- dos, procedimentos e resultados}

\author{
Searching relation medical formation and physical \\ activity: Meanings, proceedings and results \\ Aguinaldo Gonçalves ${ }^{1}$, Glauca G. Mantellini², \\ Giovani De Lorenzi Pires ${ }^{3}$, Edgard Matiello Júnior ${ }^{3}$, \\ Ana Carolina Basso ${ }^{4}$
}

Palavras-chave: Educação Médica, Autonomia Profissional, Atividade Física.

Key words: Medical

Education,

Professional

Autonomy, Physical Activity.

Correspondência: Aguinaldo Gonçalves

Rua Luverci Pereira de Souza, 1151, 13084-031, Cidade

Universitária, Campinas, SP - Brasil.

Correo electrónico: aguinaldogon@ uol.com.br

\section{Resumo}

Por proporcionar a confluência de interesses comuns, a disciplina Educação Física Curricular ministrada para calouros do curso de Medicina, se identifica como projeto de ensino/pesquisa, interessante para ser conhecido e apreciado. Trata-se de processo didático-metodológico em que se aliam práticas e reflexões participativamente planejadas, baseadas em princípios pedagógicos problematizadores para a identificação de temáticas significativas aos alunos e na interlocução/ reconstrução destes dois conjuntos. Na presente comunicação, relatamse e discutem-se respectivos resultados e significados.

\begin{abstract}
For many years, it has been issued classes of Physical Education to medical course as a regular activity. Considering the interest raised, the present communication introduces and discusses some aspects of this project. It is a didatic-methodologic process that encompasses sharing pratices and planned reflexions, based on i) pedagogical principles; ii) identifications of significant subjects to the students and iii) dialogue / rebuilding of these two conjuncts. Proceedings, results and meanings are presented and discussed with some detail.
\end{abstract}

\section{Introdução e objetivos}

Para além das últimas duas décadas de produção científica, temos elegido entre nossas identidades conceber, propor e concretizar oportunidades pedagógicas em saúde. Executa-se, em decorrência, política de formação pós-graduada contemplando diversificação de experiências investigativas e de ensino a implementar o trânsito entre teoria e prática, habitualmente não tão freqüentes quanto o desejável. Nessa perspectiva, um dos projetos vem se destacando: é o desenvolvido com universitários, expresso tanto em ensaios acadêmicos apresentados em eventos nacionais ${ }^{(1)}$, quanto veiculados em periódicos da área, eletrônicos ${ }^{(2)}$ ou não ${ }^{(3,4)}$, com apoio decisivo do Fundo de Amparo ao Ensino, Pesquisa e Extensão da Unicamp.

\begin{tabular}{|c|}
\hline $\begin{array}{l}1 \text { Médico Sanitarista, } \\
\text { Pós-Doutor em } \\
\text { Epidemiologia } \\
\text { Genética. Docente } \\
\text { Pesquisador A1, } \\
\text { Coordenador do } \\
\text { Grupo de } \\
\text { Epidemiologia e } \\
\text { Saúde, Faculdade } \\
\text { de Medicina, PUC } \\
\text { Campinas, } \\
\text { Campinas, } \\
\text { SP - Brasil. }\end{array}$ \\
\hline $\begin{array}{l}2 \text { Fisioterapeuta, } \\
\text { Doutora em } \\
\text { Atividade Física } \\
\text { Adaptada. Membro } \\
\text { Diretor, Grupo } \\
\text { Especializado em } \\
\text { Fisioterapia } \\
\text { Gerontológica, } \\
\text { Sociedade Suiça } \\
\text { de Gerontologia, } \\
\text { Zurique - Suíça. }\end{array}$ \\
\hline $\begin{array}{l}3 \text { Professor de } \\
\text { Educação Física, } \\
\text { Doutor em Educação } \\
\text { Física. Professor } \\
\text { Adjunto do Curso } \\
\text { de Educação Física, } \\
\text { Centro de Ciências } \\
\text { do Esporte, } \\
\text { Universidade Federal } \\
\text { de Santa Catarina, } \\
\text { Florianópolis, } \\
\text { SC - Brasil. }\end{array}$ \\
\hline $\begin{array}{l}4 \text { Fisioterapeuta, } \\
\text { Doutora em Saúde } \\
\text { Pública. Docente } \\
\text { da Faculdade de } \\
\text { Fisioterapia da } \\
\text { Universidade de } \\
\text { Taubaté, Taubaté, } \\
\text { SP - Brasil. }\end{array}$ \\
\hline $\begin{array}{l}\text { Recibido: } \\
27 \text { de octubre } \\
\text { de } 2011\end{array}$ \\
\hline $\begin{array}{l}\text { Aceptado: } \\
20 \text { de diciembre } \\
\text { de } 2011\end{array}$ \\
\hline
\end{tabular}


Especificamente com calouros do curso médico, a Disciplina Educação Física Curricular tem propiciado atividades desportivas e fundamentos de Formação Médica, integradamente à Saúde Coletiva. Sem abandonar o estudo sistemático em sala e tampouco a freqüência ao campo (e quadra), tem-se inovado a partir dos consensos de: i) sensibilização discente para com a atividade física (AF); ii) transferência em direção a decisões transformadoras e iii) aceitação de leque de alternativas, para os estudantes, individualmente ou em grupos, optarem pelas que mais lhes sejam pertinentes ${ }^{(5)}$. Informações colhidas em exames médicos prévios ao início do programa semestral, testes de aptidão física, e anamneses relacionadas ao nível de AF e hábitos pessoais revelaram formas distintas com que constroem eles a Saúde da Geração Saúde(6): uma das surpresas que aí se apreendeu foi a constatação de que os rapazes que referiram hábitos de tabagismo e/ou etilismo expressaram-se, no plano descritivo, mais ativos fisicamente quando comparados aos abstêmios; entre as moças, as fisicamente ativas chegaram a apresentar seis vezes mais etilismo referido que as sedentárias.

Com as decorrentes acumulações e reflexões, interessou compreender se essas aparentes contradições observadas são peculiaridades das turmas envolvidas diretamente nas aulas,ou próprias dos estudantes de Medicina. De fato, tais jovens expressam singularidades ${ }^{(7)}$, no sentido de que as normas vigentes em sua formação levam a: i) desprendimento de emoções na relação com pacientes; ii) conflitos entre dever (prevenir doenças) e reconhecimento social (curar doenças); iii) serem encarados como colegas de profissão ainda enquanto estudantes (e assim se portam, suportando precocemente elevado grau de responsabilidade). Como desdobramento desse indicativo, julgou-se procedente proposta de ensino e pesquisa em Formação Médica que permita viabilizar a eles que sintam e avaliem a AF inserida no repertório de sua quotidianeidade, com vistas a operá-la junto a quem vão exercer influência profissional posterior.

\section{Princípios gerais e específicos}

Partiu-se de compromisso com processo dinâmico de interlocução e reconstrução de saberes e fazeres ${ }^{(8)}$ em Saúde Coletiva, adotando-se procedimentos que assumam como princípios didáticos gerais:

a. Construção da autonomia: objetiva-se o estabelecimento integrado de "ferramentas", no sentido de que os alunos busquem autonomamente a ampliação de conhecimentos e a incorporação dos mesmos à vida social e acadêmica ${ }^{(9)}$;

b. Efeito multiplicador: como conseqüência do anterior, visa-se que contem com subsídios que os conduzam a multiplicadores $^{(10)}$. Aqui, leva-se em consideração que tendem a se tornar referências em suas áreas de inserção, podendo, portanto, por ações tomadas conscientemente, fazê-lo em relação à AF.

c. Ludicidade: em oposição ao caráter de performance ou aperfeiçoamento da aptidão física e por sua característica de experiência cultural sensível, prazerosa e criativa ${ }^{(11)}$, foi focado como base orientadora o oferecimento de auto e co-determinação, como momentos de suspensão temporária da realidade. Ressalta-se a especificidade destes estudantes, em virtude do processo competitivo a que foram submetidos na preparação para o ingresso. Gestos lúdicos podem se mostrar-lhes humanizadores das relações consigo mesmo, com o meio e com a sociedade.

d. Planejamento participativo: trata-se de levar o plano de estudos a ser constantemente avaliado, produzindo os chamados "temas dobradiças", articuladores dos significados do universo discente às elaborações definidas pela equipe docente. Parte-se de suas culturas de movimento, construídas em AF escolar e de lazer pregressas, para serem valorizadas e ressignificadas. A espectativa é que, incorporando o (re)conhecido, seja facilitada a apropriação ativa e crítica do novo e do superador ${ }^{(12)}$.

e. Integração (graduação/pós-graduação; ensino/pesquisa; agir/refletir): exerce-se este princípio pela articulação entre um docente e alguns de seus mestrandos e doutorandos com cento e dez primeiroanistas de graduação. A partir de então, 
geram-se condições para construir bancos de dados, analisá-los e torná-los disponíveis para a comunidade acadêmica da área com produções de relatos, comunicações e artigos, que já perfazem total superior a 400 publicações $^{(13)}$.

\section{Material e métodos}

No nível da execução, por via de conseqüência, adotaram-se os passos sugeridos por Freire $(1983)^{(14)}$, a saber: i) apresentação de plano exploratório para a Disciplina, com conteúdos considerados "necessários" pelos critérios já referidos; ii) identificação de temáticas significativas aos alunos, através de inventário biográfico de sua cultura de movimento; iii) interlocução e reconstrução destes dois conjuntos de saberes e fazeres, produzindo programa de ensino superador, portanto, dos anteriores, apresentado no quadro 1. Destaque-se ainda o caráter de flexibilidade e avaliação permanente que permitiu a este planejamento refazer-se repetida e dialogicamente.

Quadro 1. Programa apresentado para montagem inicial do Planejamento Participativo

Apresentação. Identificação das temáticas significativas no universo dos alunos

Avaliação médica

Testes de Aptidão Física

Intensidade do Esforço

Passeio assistido (no Parque do Lago)

Saúde, doença e intervenção

Esporte, mídia e encenações pedagógicas

Atividade Física e tempo livre

Na versão mais recentemente oferecida, foram constituídas duas turmas, cada uma delas com 55 alunos, com duas aulas semanais de 50 minutos cada, realizadas de modo seqüencial. Para ambas estavam previstos os mesmos procedimentos, embora se admitisse que, em virtude das peculiaridades que as conformam, diferenças de estratégias e ritmos pudessem se diversificar. Os profissionais tiveram asseguradas prerrogativas para orientar, a partir de fundamentação comum básica, sua atuação de forma julgada mais apropriada. No entanto, como se tratou de planejamento participativo, durante todo o processo sempre houve momentos para avaliação e reorientação.

De imediato, introduzidos os protagonistas, o projeto foi exposto na primeira aula. Todos os participantes receberam, para apreciação e posterior discussão, respectivo programa preliminar. A seguir, entregou-se, a cada um, formulário para coleta das informações relativas ao segundo passo já enunciado. De posse da exploração de tais dados, foram reunidos de sorte a contemplar interesses que preservassem os princípios originais. Dois de nós (G.L.P. e E.M.J.) ficamos à disposição dos demais para a consecução desta fase.

Sob orientação docente contínua e proximal, foram alocados para cada aula, dois integrantes do Grupo: um responsável e outro, auxiliar. A aula seguinte era ministrada pelo auxiliar da anterior, agora na qualidade de responsável, e assim sucessivamente. Isto evitou que ocorressem fragmentações e que ministrante e alunos se conhecessem apenas no dia da aula.

Coerentemente com o apontado na seção anterior, a investigação foi de natureza qualiquantitativa, buscando recolher evidências que permitissem descrever e avaliar o alcance da intervenção. Vários foram os recursos utilizados como equipamentos de avaliação física: cronômetros, formulários impressos, filmadora, predominando a utilização diretamente pelos próprios alunos. Nessa direção, também variadas se fizeram as dependências utilizadas: a partir do encontro em sala, partia-se quase sempre para ambientes externos, como as quadras, sala de ginástica e o Parque do Lago. Foram processadas filmagem e registro fotográfico. Este conjunto de dados foi catalogado, transcrito, sistematizado e submetido, nas sucessivas etapas de registro e interpretação, a análise de conteúdo.

Esta consiste em forma de hermenêutica controlada, aplicável a discursos diversificados, gerada pela inclusão de amplo espectro composto desde o rigor da objetividade até a fecundidade da subjetividade. Em outros termos, delimita-se segunda leitura atenta e fecunda, que transcende o olhar imediato e espontâneo do leigo, por estruturar-se em consensos 
próprios. Especificamente, adotou-se a modalidade categorial, em que se recolhe o saber/agir do entendimento textual e se busca apreender a idéia principal de cada segmento sob estudo, isolando-a ao lado das demais, para compor listagem de temas ou itens assim recuperados. As categorias são rubricas ou classes, que reúnem elementos sob título genérico e em razão de caracteres comuns dos mesmos. O critério de categorização pode ser semântico, sintático, lexical e expressivo(15). Mais amplamente, todas as fases da intervenção foram miradas, pela perspectiva da metodologia qualitativa, através da abordagem do interacionismo simbólico, permeando a apreensão e análise de pistas eliciadas, como expressões adotadas de linguagem não verbal e registro de fatos e ocorrências, significados pelas circunstâncias e detalhes reveladores para olhos de querer ver ${ }^{(16)}$, i.e. demarcados pela intencionalidade e exaustão, os dois balizadores desta abordagem.

Apesar da complexidade que, inerentemente, dificulta um relato detalhado, explicitam-se, a seguir no quadro 2, os "temas dobradiças" implementados e respectivos identificadores. Como aí se constata pela observação imediata, trata-se de atividades desenvolvidas por coerência com os princípios gerais e específicos inicialmente mencionados e implementados, contemplando

Quadro 2. Explicitações dos "temas dobradiças", segundo oportunidade de aplicação, caracterizados por respectivas ações e recursos.

\begin{tabular}{|c|c|c|}
\hline \multirow{2}{*}{ "Temas dobradiças" } & \multicolumn{2}{|c|}{ Oportunidade de aplicação } \\
\hline & Primeira aula & Segunda aula \\
\hline Testes de Aptidão Física & - exposição teórica com demonstrações práticas. & 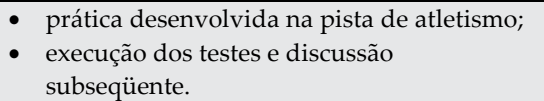 \\
\hline Intensidade de esforço & $\begin{array}{l}\text { - exposição do conceito, apresentação das } \\
\text { metodologias utilizadas para aferição e } \\
\text { aplicação em atividades anaeróbias; } \\
\text { - discussão dos resultados colhidos. }\end{array}$ & $\begin{array}{l}\text { - mesmos procedimentos, mas com atividades } \\
\text { aeróbias; } \\
\text { - discussão da diferença do comportamento } \\
\text { da intensidade de esforço nas modalidades } \\
\text { intermitente e na contínua. }\end{array}$ \\
\hline $\begin{array}{l}\text { Passeio Assistido (no } \\
\text { Parque do Lago) }\end{array}$ & $\begin{array}{l}\text { - apresentação da proposta de trabalho e } \\
\text { respectiva fundamentação teórica, baseada } \\
\text { principalmente na Pedagogia Crítico- } \\
\text { emancipatória (Kunz, 1994); } \\
\text { - reconhecimento do Parque do Lago; } \\
\text { - discussão preliminar de possibilidades de } \\
\text { desenvolvimento de atividades que } \\
\text { privilegiassem a ocupação do espaço natural, } \\
\text { com caráter lúdico e integrador do grupo; } \\
\text { - formação de quatro grupos de trabalho para } \\
\text { formulação e aplicação de atividades na aula } \\
\text { subsequente, considerando as experiências } \\
\text { motoras e as aulas anteriores da atual } \\
\text { disciplina. }\end{array}$ & $\begin{array}{l}\text { - execução das propostas dos subgrupos } \\
\text { (jogos) com avaliação intermediária e final } \\
\text { do processo. }\end{array}$ \\
\hline $\begin{array}{l}\text { Saúde, Doença e } \\
\text { Intervenção }\end{array}$ & $\begin{array}{l}\text { - vivência de atividades de relaxamento, } \\
\text { alongamento muscular e futebol cooperativo, } \\
\text { segundo roteiro previamente elaborado; } \\
\text { - preenchimento de protocolo de avaliação das } \\
\text { atividades desenvolvidas. }\end{array}$ & $\begin{array}{l}\text { - discussão sobre qualidade de vida, saúde, } \\
\text { doença e intervenção. }\end{array}$ \\
\hline $\begin{array}{l}\text { Esporte, mídia e encenações } \\
\text { pedagógicas }\end{array}$ & $\begin{array}{l}\text { - exposição de dois referenciais teóricos: i) a } \\
\text { dramaturgia social ou "teoria dos papéis } \\
\text { sociais", de Erving Goffman; ii) as encenações } \\
\text { pedagógicas do esporte, propostas por Dietrich } \\
\text { et Landau } 17 \text {; } \\
\text { - prática de jogo de uma modalidade esportiva } \\
\text { coletiva, registrada por equipes de filmagem. }\end{array}$ & 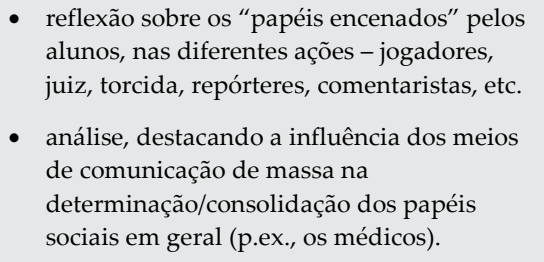 \\
\hline $\begin{array}{l}\text { Atividade Física de tempo } \\
\text { livre }\end{array}$ & $\begin{array}{l}\text { - desenvolvimento de atividades recreativas, } \\
\text { como: barra manteiga, bola de gude, pular } \\
\text { corda, rodar pião, queima e betes. }\end{array}$ & $\begin{array}{l}\text { - "Caça ao Tesouro" com perguntas sobre } \\
\text { questões básicas de Saúde Coletiva e debate } \\
\text { a seguir. }\end{array}$ \\
\hline
\end{tabular}


com característica identitária sua realização coletiva e solidária, bem como, sempre que possível, em ambientes não isolado nem individual, mas natural ou social, como já marcadamente destacado, i.e., em parque e quadra $^{(17)}$.

No final da disciplina foram coletadas apreciações sobre o curso através de instrumento padronizado, seguidas de discussão plenária sob coordenação docente e que constituem o objeto dos resultados quantitativos e qualitativos relatados no próximo segmento.

Todos os procedimentos descritos acima estão e foram aplicados em consonância com os princípios éticos norteadores das resoluções vigentes do Conselho $\mathrm{Na}$ cional de Saúde do Brasil e da Conferência de Helsinque para Pesquisas Envolvendo Seres Humanos.

\section{Resultados}

\section{Resultados Quantitativos}

Ao final do processo, em avaliação empreendida por formulário específico e de respostas individuais, as questões maiores colocadas apontaram para o atendimento ao caráter lúdico da proposta; a estimulação para auto-organização dos grupos, bem como a insistência por assunção de valores como cooperação, respeito, solidariedade, altruísmo, cuidado, dentre outros. Pontualmente, a tabela 1 indica respectivas distribuições de freqüências absoluta e relativa. Visando aprimoramento em aplicações posteriores, foram ainda pontuadas 17 sugestões enumeradas na tabela 2: em síntese revelam que embora a maioria dos alunos "quer mais do mesmo", a apreciação dos aspectos mencionados como negativos ou indicações de melhora para os próximos cursos aponta para a aquisição, pelos mesmos, de consciência crítica em direção à autonomia.

\section{Resultados Qualitativos}

A proposta de que os ministrantes conhecessem as turmas, pelo menos na se- mana anterior à aula de sua responsabilidade, foi atendida e bem avaliada, a ponto de obterem-se gradualmente melhores desempenhos. Também é exemplificador o quanto a divisão de tarefas pode facilitar o trânsito junto a turmas numerosas.

Chamaram atenção nos relatórios e nas discussões preliminares algumas revelações bem visíveis: i) inicialmente, não chegaram muito animados, dando pistas de certa indisposição para o que julgavam atividades secundárias, a partir de sua situação de "calouros da Medicina" - o que parece ter se alterado, com o fato de os mesmos se tornarem bastante interessados ao longo do tempo; ii) em sala de aula, foram ruidosos, chegando a tomarem atitudes habitualmente não praticadas (colocar pés nas cadeiras, por exemplo), o que pode ser derivado da descontração atingida apenas na Educação Física; iii) houve maior interesse e aderência a ocupações externas, quando se empenharam intensamente em jogos e brincadeiras; iv) o número reduzido de presentes facilitou a proximidade entre si em algumas situações, ao mesmo tempo em que valorizavam a aula, independente do número.

Num dos exercícios, o do futebol com regras adaptadas, havia um dos alunos que normalmente não tomava parte, por restrições médicas para AF. No entanto, como se demonstrou que a proposta não exigiria tanto em termos de intensidade e esforço, convenceu-se e participou - aliás, foi dos que mais o fizeram! Este fato demarca o questionamento, pelo menos, de um lado, para com os exames médicos para fins de prática desportiva e, por outro, dos objetivos postos.

Em termos de desdobramentos de médio prazo, numerosas foram as manifestações da comunidade acadêmica local acerca desta iniciativa, contando-se entre as mais freqüentemente recolhidas:

i. o caráter de pioneirismo da proposta concretizada, o que, realmente fez com que praticamente todos os aspectos conceituais e operacionais envolvidos não contassem com antecedentes que pudessem guiar ou, ao menos, contribuir para a efetivação dos mesmos; 
ii. o fato, comentado pelos colegas responsáveis pelo ensino de Propedêutica e pela coordenação do curso, que seus alunos, após cursarem esta Educação Física Curricular, demonstravam-se mais seguros e à vontade nas relações humanas da iniciação semiológica, especialmente nos procedimentos de palpação e percussão, dado que tinham aprendido a lidar melhor com a aproximação e o toque entre as pessoas;

iii. Sua absoluta excepcionalidade, por ter sido mantida em vigência por mais alguns anos por decisão da Congregação da Unidade, não obstante a realização da reforma curricular havida, que alterou a imensa maioria das demais Disciplinas;

iv. $\mathrm{O}$ aspecto adicional de sua relevância, por introduzir concretamente o estudante de Medicina à realidade da AF na prevenção e controle das doenças crônico-degenerativas pelo combate à hipocinesia e competitividade paradigmáticas do mundo e da morbidade atuais;

v. A geração de consciência critica da necessidade de o curso desenvolver conteúdos referentes, minimamente, a questões do âmbito de Fisiologia do Esforço e Cinesiologia/Cinesioterapia, já presentes na formação de outros profissionais integrantes da equipe de saúde, embora com alcance mais circunscrito que o do médico;

vi) A amplamente reconhecida aplicação, no exercício profissional deste, das vivências aqui apreendidas, não exclusivamente em termos de competência técnica, mas inclusive de valores humanos de convivência e solidariedade.

\section{Discussão}

A investigação relatada traz como questão central à reflexão em que medida a Formação Médica pode incluir em sua composição a AF sistemática dimensionada no contexto aqui apresentado.

A observação da evolução comporta, com segurança, resposta afirmativa, posto que vem se tornando contemporaneamente verdadeira trajetória de (re)humanização, em direção à superação dos limites reconhecidamente existentes ${ }^{(18)}$ em sua modernização desde o início do século $X X$, com o famoso relatório Flexner a enfatizar a formação experimental de base sub-individual, proveniente de pesquisa básica, bem como a especialização excessivamente precoce dentro do ambiente intra hospitalar.

De fato, na recuperação dos fatos recentes envolvidos em tal realidade, Almeida $(2001)^{(19)}$ situa a Segunda Conferência Mundial de Educação Médica, havida em Edimburgo em 1993, ao lado da Conferência Integrada Universidade Latino-Americana e Saúde da População (em Havana, 1992) como os dois eventos importantes/processos internacionais "que serviram para acumular conhecimento e poder por parte dos atores do movimento continental". O referido texto revela que, no interior do acontecimento citado, o documento de posicionamento das Américas, de autoria inclusive da Organização Pan-americana da Saúde, registra a necessidade de outro paradigma educativo, em função do indivíduo e da sociedade; reconhece a seguir, como conseqüência, a carência por novo sistema de valores interdisciplinares. Poucos anos após, Campos (1999)(20) estudou numerosas Faculdades de Medicina no país: partindo do pressuposto de que a principal qualidade dos médicos consiste na capacidade de resolver problemas, o que implica aspectos biológicos, subjetivos e sociais, conclui pela inadequação do então e ainda hoje presente modelo de treinamento clínico.

Felizmente, esta década vem registrando entre nós vigoroso movimento de transformação existente, constituído não somente por dirigentes, especialistas e comunidades acadêmicas, mas instituições decisórias de nível federal, estadual e local, pois Siqueira (2001) (21) identificou que, desde então, existe no Brasil, no conjunto de diferentes grupos de escolas médicas, aquele que procura investir na capacidade metodológica e política que leva ao aluno situar-se mais próximo do real e do aplicado.

Em síntese, cabe lembrar a observação de Lima Gonçalves (2001)(22), que, referindo-se a AF como "competições desportivas", encontra-lhe dois sentidos antagônicos: se por um lado, constituir-se-ia, no dizer do autor, em "fator de ansiedade", por outro, encerra "alto conteúdo formativo", seja pela 
socialização que promove, seja pela influência na saúde física e emocional. Em outros termos, em nossos dias, superando-se, como vimos, o primeiro aspecto mencionado por exercícios físicos e atos motores diversificados, autênticos e mais amplamente considerados, busca-se deliberadamente o segundo.

\section{Financiamiento}

Projeto parcialmente financiado pelo Fundo de Apoio ao Ensino, Pesquisa e Extensão (FAEPEX/Unicamp).

\section{Declaração de autoria e conflitos de interesse}

AG concebeu, coordenou, redigiu e reviu todo o projeto e texto original, com apoio direto de GGM. Todos os autores participaram das fases de formulação, execução e relato. Os autores declaram não haver conflitos de interesse.

\section{Referências}

1. Ramos MG, Gonçalves A. (1995). O Ensino da Educação Física na Unicamp e a atuação do Departamento de Ciências do Esporte: o atendimento da comunidade. Anais do $4^{\circ}$ Seminário Nacional de Educação Física no Terceiro Grau; 1995 out 11-14; São Paulo: Pontifícia Universidade Católica, p. 17.

2. Gonçalves A. (2006). Provocando integrações latino-americanas da Educação Física. Conexões, 4(2):66-71.

3. Ramos MG, Gonçalves A. (1998). Educação Física no Terceiro Grau: aspectos da experiência da Universidade de Campinas. Revista Brasileira Ciências Esporte, 19(2):25-30.

4. Gonçalves A, Conte M, Oliveira PR. (1997). A Saúde da Geração Saúde: ensino e pesquisa sobre hábitos e habilidades físicas de calouros da Faculdade de Ciências Médicas da UNICAMP. Anais do $3^{\circ}$ Congresso Nacional da Rede Unida; nov 18-21; Salvador: Rede Unida, p.158.

5. Gonçalves A, Conte M, Pires GL, Oliveira PR. (1997). A Saúde da Geração Saúde: Pesquisa e Ensino sobre capacidades físicas e referências a hábitos e morbidade dos calouros da Faculdade de Ciências Médicas da UNICAMP. Revista Brasileira Atividade Física Saúde, 2(4):41-58.
6. Conte M, Gonçalves A. (1998). Condições de Vida da Geração Saúde I: tabagismo, etilismo e nível de atividade física dos calouros da Faculdade de Ciências Médicas da Unicamp. Anais do $4^{\circ}$ Congresso Brasileiro de Epidemiologia, ago 03-07; Rio de Janeiro: Associação Brasileira de Saúde Coletiva, p. 491.

7. Conte M, Gonçalves A. (2006). Ampliando elementos da Educação Médica: Morbidade Referida em Universitários de Medicina. Revista Brasileira Educação Médica, 30(1):15-19.

8. Marques MO. (1996). Educação/interlocução, aprendizagem/reconstrução de saberes. Ijuí: Unijuí.

9. Kunz E. (1994). Transformação didático-pedagógica do esporte. Ijuí: Unijuí.

10. Pires G, Matiello Jr E, Gonçalves A. (1999). Lazer: um princípio educativo para a Educação Física Curricular Universitária. Movimento, 5(11):74-84.

11. Marcellino NC. (1999). Lúdico e lazer. In: __(org.). Lúdico, educação e educação física. Ijuí: Unijuí.

12. Conte M, Gonçalves A, Chalita LVAS, Carvalho L. (2008). Nível de Atividade Física como estimador de Aptidão Física de estudantes universitários: explorando a adoção de questionário através de modelagem linear. Revista Brasileira Medicina do Esporte, 14(4): 332-336.

13. Leo CCC, Gonçalves A. (2008). Aplicando metodologias: recortes da experiência do Grupo de Saúde Coletiva e Atividade Física da Unicamp. Revista Educação Fisica Universidade Estadual de Maringá, 19(4):529-538.

14. Freire P. (1983). Pedagogia do oprimido. Rio de Janeiro: Paz e Terra.

15. Mantellini GG, Gonçalves A. (2009). A revisão e a análise como metodologias científicas conteudísticas. Inter Science Place, 2(5):1-13.

16. Gonçalves A. (2009). A Saúde Coletiva no Manuel Sérgio Contemporâneo (Resenha). Cadernos de Saúde Pública, 18(3):890-891.

17. Haguette MTF. (1987). Metodologias qualitativas na sociologia. Petrópolis: Vozes.

18. Ronzani TM, Ribeiro MS. (2003). Identidade e formação profissional dos médicos. Revista Brasileira de Educação Médica, 27(3):229-239.

19. Almeida MJ. A Educação Médica e as atuais propostas de mudança: alguns antecedentes históricos. Revista Brasileira de Educação Médica. 2001; 25(2):42-52.

20. Campos GWS. (1999). Educação médica, hospitais universitários e o Sistema Único de Saúde. Cadernos de Saúde Pública, 15(1):187-193.

21. Siqueira BP. (2001). Repensando a arte de ensinar a ciência da vida. Medicina Conselho Federal, 16(131):8-9.

22. Gonçalves EL. (2001). Ser médico: uma longa trajetória. Revista do Hospital das Clinicas da Universidade de São Paulo, 11(12): 22-29. 